\title{
Outcome of patients fed via a nasogastric tube retained with a bridle loop: do bridle loops reduce the requirement for percutaneous endoscopic gastrostomy insertion and 30-day mortality?
}

\author{
R. D. Johnston, L. O’Dell, M. Patrick, A. T. Cole and R. N. Cunliffe \\ Southern Derbyshire Acute Health Trust, Derby City General Hospital, Uttoxeter Road, Derby DE22 3NE, UK
}

Between 40 and $80 \%$ of feeding nasogastric tubes (NGT) become dislodged ${ }^{(1,2)}$. This results in feeding delays, wasted staff time and an increased risk of aspiration if the tube becomes partially displaced. The use of nasal bridle loops has been shown to have very few complications and minimal discomfort ${ }^{(3)}$. It improves nutritional intake and allows some stroke patients to recover their swallow and so avoid PEG insertion $^{(4)}$. A previous non-randomised study suggested that they may reduce the PEG-related mortality ${ }^{(5)}$.

Within our Trust the policy is to insert a bridle loop following the removal of three standard feeding NGT. Contraindications include fractured facial or cranial bones, obstructed nasal passages and the severely agitated patient who is deemed likely to traumatise themselves via traction on the tube. Applied Medical Technologies (AMT) bridle loops are used and inserted at the bedside by one of our three trained nutrition nurses. NG tubes are passed using standard techniques. 15-gauge Freka PEG tubes are placed endoscopically with antibiotic prophylaxis.

We prospectively collected data on patient demographics, indications and outcome for our NG bridle loop service run throughout our trust from May 2006 to May 2007. PEG related mortality rates were also collected before and during the study period.

A total of fifty-three patients were referred for a bridle loop and forty-five (85\%) were successfully placed, mean age 79 (range 36-98) years, $58 \%$ male. Of the forty-five patients, the majority $(n+40)$ were medical patients, one surgical, one ICU, two rehab. and one a community hospital patient. Their underlying diagnoses were a stroke $(n 24)$, other neurology $(n 8)$, dementia $(n 5)$, alcoholic liver disease (n 5) and other pathologies (n 3).

Of the eight with unsuccessful insertion, five did not tolerate the bridle loop insertion, one patient refused, one had a prior nasal fracture and one was too agitated.

No patient removed the bridle loop, but twenty out of twenty-five removed the NGT with the bridle remaining in situ. Of these twenty patients, nine had the NGT re-inserted and re-secured with a bridle loop, seven proceeded to PEG, three re-gained normal swallow and one died prior to further intervention.

The bridle loop was removed by staff in one patient due to the patient applying excessive traction on the tube. The only complication was minor self-limiting nasal bleeding at the time of insertion in three patients. No bridle loop was removed due to complications or discomfort.

The principal outcome at 30 days is shown in table 1 . Using a $\chi^{2}$ test there were no statistically significant differences in outcomes between those having a bridle or not.

\begin{tabular}{llccc} 
Table 1. Principal outcome at 30 days & & \\
\hline \multicolumn{1}{c}{ Outcome } & No. of pts & $\begin{array}{c}\text { Median time to } \\
\text { outcome (days) }\end{array}$ & $\begin{array}{c}\text { Range } \\
\text { (days) }\end{array}$ \\
\hline $\begin{array}{l}\text { No bridle, } \\
\mathbf{n}=\mathbf{8}\end{array}$ & Oral feeding & $2(25 \%)$ & 3.5 & $2-5$ \\
& Continued NG feeding & 0 & - & - \\
& PEG inserted & $3(38 \%)$ & 1.7 & $1-3$ \\
Bridle placed, & Died & $3(38 \%)$ & 15.7 & $3-27$ \\
$\mathbf{n}=\mathbf{4 5}$ & Oral feeding & $11(24 \%)$ & 11.2 & $2-28$ \\
& Continued NG feeding & $2(4 \%)$ & 30 & 30 \\
& PEG inserted & $19(42 \%)$ & 10.7 & $1-23$ \\
& Died & $13(29 \%)$ & 9.6 & $3-30$ \\
\hline
\end{tabular}

Thirty-day PEG mortality rates prior to the use of bridle loops were $28 \%$ (twenty-three out of eighty-three) and $11 \%$ (twelve out of $109)$ during the study period $\left(\chi^{2}=7.2, \mathrm{p}<0.01\right)$. Thirty-day mortality rates for those with a bridle were $29 \%$ (thirteen out of forty-five). The combined PEG and bridle mortality rates were $28 \%$ (twenty-three out of eighty-three) pre and $16 \%((12+13) /(109+45))$ during the study period $\left(\chi^{2}=3.5, \mathrm{p}<0.10\right)$.

The bridle loop service provided nutrition to patients who would otherwise have failed to receive enteral nutrition without a PEG. PEG insertion was avoided in the majority (58\%). Thirty-day PEG-related mortality fell following the introduction of the bridle service from $28 \%$ to $11 \%$. This may in part be explained by the bridle loops allowing a better selection of patients for the PEG. Bridle loops allowed patients on average a valuable $10 \mathrm{~d}$ of nutrition prior to either recovering or succumbing from their illness or a PEG being placed.

It is now time for a fully randomised and prospective study to confirm whether bridle loops truly reduce PEG insertion rates and overall 30-d mortality in patients who are unable to retain a standard NGT.

1. Meer JA (1987) J Parenteral and Enteral Nutrition 11, 187-189.

2. Keohane PP, Attril H, Jones BJ \& Silk DB (1983) Clin Nutr 2 (2), 85-86.

3. Popovich MJ, Lockrem JD \& Zivot JB (1996) Crit Care Med 24 (3), 429-431.

4. Anderson MR, O'Connor M, Mayer P, O’Mahony D, Woodward J \& Kane K (2004) Clin Nutr 23, 501-506.

5. Donaldson E, Earley T \& Sheilds PL (2007) Gut 56, suppl. 11, A137. 